\title{
Surgical Treatment of $\mathrm{C}$ hiari I $M$ alformation: Simplified Technique and C linical R esults
}

\author{
Michael B. Pritz, M.D., Ph.D.1
}

\begin{abstract}
A simplified technique for decompressing the posterior fossa and foramen magnum in symptomatic patients with a $\mathrm{C}$ hiari I malformation is described. The approach uses a curvilinear dural incision and an autologous pericranial graft. T his procedure was used in 14 symptomatic patients, 8 of whom had a cervical or cervicothoracic syrinx. N eurologic signs and symptoms improved or were unchanged in all patients. The size of the syrinx decreased in all patients. N o patient developed a new neurologic deficit, cerebrospinal fluid leak, pseudomeningocele, or infection. Postoperatively, one patient developed new, dysesthetic, unilateral arm pain that did not require medication. This technique has several advantages. The procedure is simple and requires a single skin incision. A utologous graft can be used. The occipital sinus can be avoided. Finally, the contralateral region remains pristine if a repeat procedure becomes necessary.
\end{abstract}

KEYWORDS: Chiari I malformation, surgical technique, treatment

Surgery is the treatment of choice for symptomatic patients with a $\mathrm{C}$ hiari I malformation either without or with a spinal cord syrinx. In symptomatic individuals without hydrocephalus or another structural lesion to explain cerebellar tonsillar herniation, various surgical procedures have been used with different degrees of success. ${ }^{1-4}$ Because the volume of the posterior fossa is small in C hiari I patients, ${ }^{5}$ decompression of the foramen magnum and posterior fossa has been the mainstay of surgical treatment. This report describes a simplified technique for posterior fossa and foramen magnum decompression that has proven successful in symptomatic patients with a C hiari I malformation.

Skull Base, volume 13, number 3, 2003. A ddress for correspondence and reprint requests: M ichael B. Pritz, M .D., Ph.D., Indiana U niversity School of M edicine, Section of N eurological Surgery, 545 Barnhill D rive, Emerson H all 139, Indianapolis, IN 46202-5124. E-mail: mpritz@iupui.edu. 1I ndiana U niversity School of M edicine, Section of N eurological Surgery, Indianapolis, Indiana. C opyright $\odot 2003$ by Thieme M edical Publishers, Inc., 333 Seventh A venue, N ew York, NY 10001, USA. Tel: +1(212) 584-4662. 1531-5010,p;2003,13,03, 173,178,ftx,en;sbs00348x. 


\section{MATERIAL AND METHODS}

\section{Patients}

Fourteen patients ( 5 men and 9 women) underwent the surgical procedure described below. Their ages ranged from 18 to 65 years. Eight patients (57\%) had an associated syrinx. All patients were symptomatic. N o patient had arachnoiditis, hydrocephalus, or other intracranial structural pathology aside from the $\mathrm{C}$ hiari I malformation. Postoperative neurologic examinations and imaging studies were performed at regular intervals (range, 4 months to almost 3 years). Follow-up is ongoing in most patients.
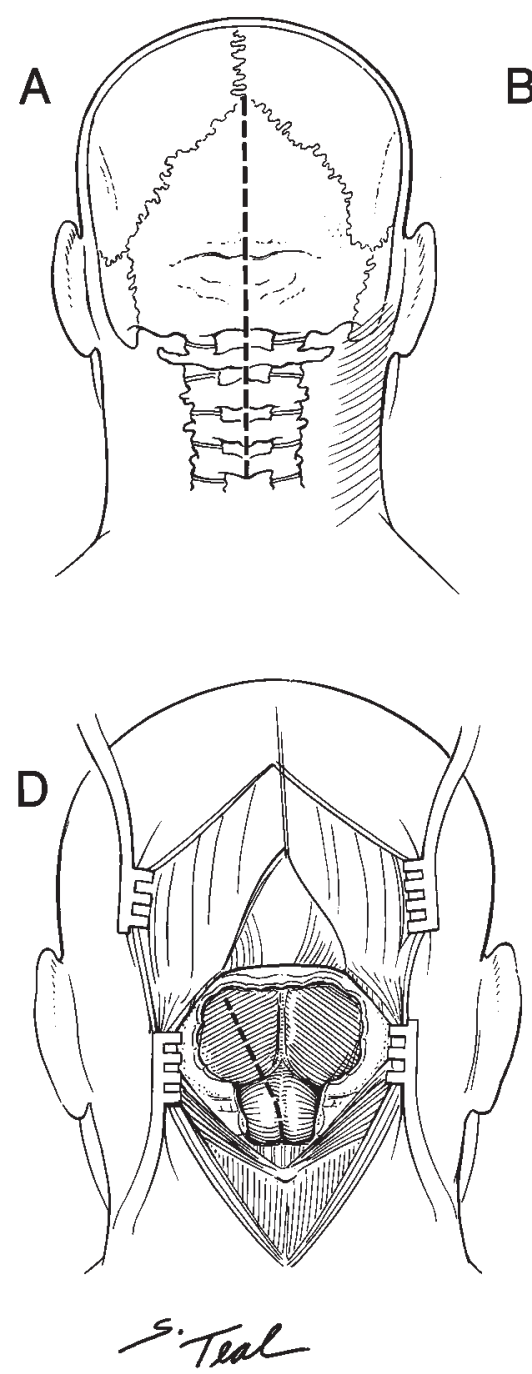

(C) IUSM Visual Media
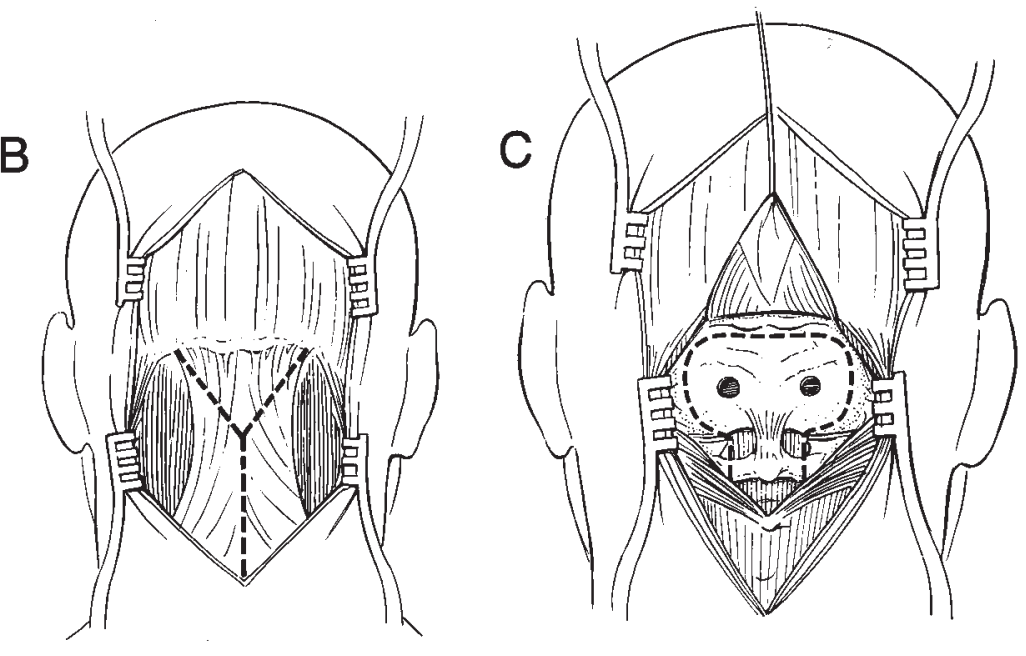

E

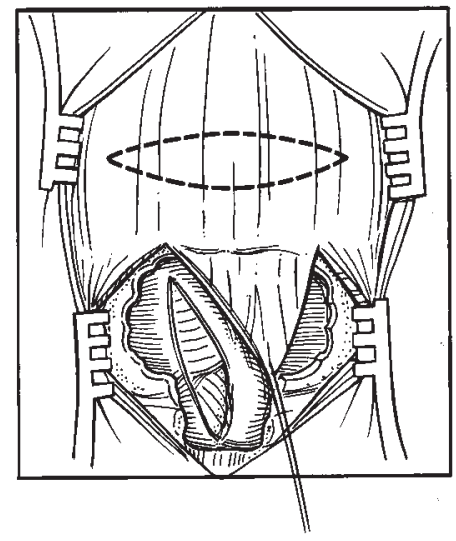

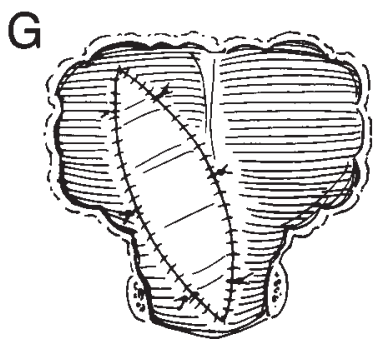

Figure 1 Surgical technique for Chiari I decompression. (A) Midline skin incision. (B) Y-shaped fascial opening. (C) Placement of trephines. (D) Dural incision. (E) Harvest of diamond-shaped pericranial patch. (F) Pericranial patch is sewn in place. (G) Final appearance of dural closure with patch graft. 


\section{Surgical Technique}

U nder general anesthesia, patients are placed prone in skeletal fixation with the head elevated and all pressure points padded. $\mathrm{H}$ air is shaved from the occipital area to the upper neck. Perioperative antibiotics are administered parenterally. $M$ agnifying loupes are used for the procedure. An incision is outlined beginning about $7 \mathrm{~cm}$ above the inion and extending downward in the cervical area based on the inferior location of the cerebellar tonsils (Fig. 1A). The incision is carried down to the pericranium and fascia. The occipital scalp is undermined to provide adequate exposure for the donor graft. The fascia is opened in a Y-shaped fashion (Fig. 1B). ${ }^{6}$ Trephines are placed in the suboccipital area (F ig. 1C). A suboccipital craniectomy is performed, followed by a cervical laminectomy based on the intradural pathology and extent of tonsillar descent (Fig. 1D). T he dura is incised in a curvilinear fashion avoiding the occipital sinus (Fig. 1D ). The arach- noid is opened and obvious adhesions are freed. A diamond-shaped pericranial patch is harvested from the occipital area and shaped to fit the dural defect (Fig. 1E ). A piece of G elfilm is placed over the exposed cerebellum and upper spinal cord. The pericranial patch is sewn in place using double-arm 5-0 prolene sutures in a fashion similar to that used to close a patch graft for arterial reconstruction ( $\mathrm{Fig}$. $1 F$ and $G$ ). The integrity of the closure is ascertained and any areas of leakage are repaired. The suture line is covered with biological adhesive. The incison is closed in anatomical layers. ${ }^{6} \mathrm{No}$ drain is used.

\section{RESULTS}

Preoperatively, patients exhibited a variety of signs and symptoms (Table 1), which are presented in a format used by others. ${ }^{7}$ The inferior extent of the

Table 1 Clinical Results in 14 Patients with Chiari I Malformation without or with Syringomyelia

\begin{tabular}{|c|c|c|c|c|c|c|c|c|}
\hline \multirow[b]{2}{*}{ Symptom/Sign } & \multicolumn{4}{|c|}{$\begin{array}{l}\text { Preop Status } \\
\text { (No. Patients) }\end{array}$} & \multicolumn{4}{|c|}{$\begin{array}{l}\text { Postop Status } \\
\text { (No. Patients) }\end{array}$} \\
\hline & Absent & Mild & Moderate & Severe & Absent & Mild & Moderate & Severe \\
\hline \multicolumn{9}{|l|}{ Symptom } \\
\hline Headache & 12 & 1 & 1 & 0 & 13 & 1 & 0 & 0 \\
\hline Dysesthetic pain & 13 & 0 & 1 & 0 & 12 & 2 & 0 & 0 \\
\hline Subjective weakness & 9 & 1 & 3 & 1 & 11 & 3 & 0 & 0 \\
\hline Sensory loss by Hx & 8 & 1 & 2 & 3 & 8 & 5 & 1 & 0 \\
\hline Oscillopsia & 11 & 0 & 1 & 2 & 12 & 2 & 0 & 0 \\
\hline Paresthesias & 7 & 1 & 6 & 0 & 9 & 5 & 0 & 0 \\
\hline Dysphagia & 10 & 0 & 4 & 0 & 12 & 2 & 0 & 0 \\
\hline Chronic cough & 12 & 0 & 1 & 1 & 14 & 0 & 0 & 0 \\
\hline Weak voice & 12 & 1 & 1 & 0 & 14 & 0 & 0 & 0 \\
\hline Sleep apnea & 13 & 0 & 1 & 0 & 14 & 0 & 0 & 0 \\
\hline Impaired balance & 8 & 0 & 6 & 0 & 8 & 6 & 0 & 0 \\
\hline \multicolumn{9}{|l|}{ Sign } \\
\hline Weakness on examination* & 10 & 1 & 2 & 1 & 11 & 3 & 0 & 0 \\
\hline Atrophy & 11 & 2 & 0 & 1 & 12 & 2 & 0 & 0 \\
\hline Sensory loss on examination & 7 & 3 & 2 & 2 & 8 & 5 & 1 & 0 \\
\hline Nystagmus & 10 & 1 & 0 & 3 & 10 & 4 & 0 & 0 \\
\hline Vocal cord paresis & 13 & 0 & 0 & 1 & 13 & 1 & 0 & 0 \\
\hline Gait impairment & 9 & 1 & 4 & 0 & 10 & 4 & 0 & 0 \\
\hline
\end{tabular}

*Weakness is defined as absent (5/5), mild (4/5), moderate (3/5; antigravity strength), severe (1-2/5; < antigravity strength). $\mathrm{Hx}$, history; no., number; preop, preoperative; postop, postoperative. 
cerebellar tonsils was $6 \mathrm{~mm}$ below the foramen magnum in 1 patient, at the posterior arch of $\mathrm{C} 1$ in 11 patients, and at the posterior arch of $\mathrm{C} 2$ in 2 patients. Eight patients had a syrinx, which was confined to the cervical area in 3 patients and to the cervicothoracic region in 5 patients ( $F$ igs. $2 A$ and $B$ ).

Postoperatively, signs and symptoms either improved or were unchanged in all 14 patients. 0 ne patient developed new, unilateral dysesthetic arm pain but required no medication (Table 1 ). $T$ he size of the syrinx decreased in all patients (F ig. 2C) based on studies performed 9 months to nearly 3 years after surgery. No patient experienced a new neurologic deficit, wound infection, cerebrospinal fluid leak, pseudomeningocele, or recurrent syrinx after an initial decrease in syrinx size. $\mathrm{N}$ o patient declined neurologically during the interval of postoperative follow-up.

\section{DISCUSSION}

Various surgical approaches have been described to treat Chiari I malformations without and with a spinal cord syrinx. ${ }^{1-4}$ The present technique has proven successful in terms of treatment of both clinical signs and symptoms. Radiologic evidence has documented a decrease in syrinx size. Although somewhat controversial, opening the arachnoid allows direct inspection of structures at the craniocervical junction. In certain instances, inspection has led to additional bone removal and to the separation of arachnoidal adhesions. No patient developed a cerebrospinal fluid leak, pseudomeningocele, or infection. No patient incurred a new neurologic deficit after surgery, although a single patient developed mild, dysesthetic, unilateral arm pain that did not require medication. Follow-up has been rel-

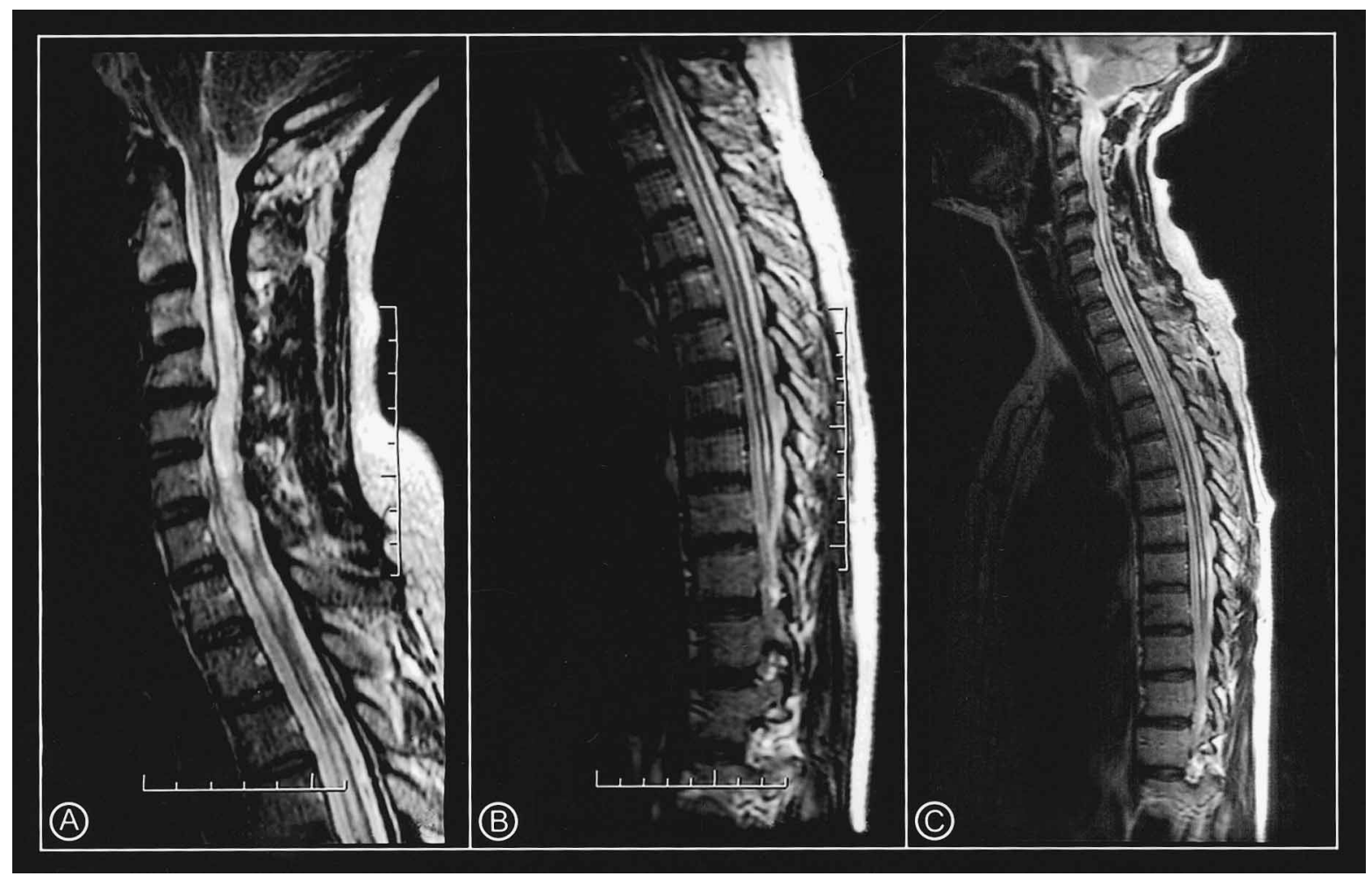

Figure 2 Pre- and postoperative images of a symptomatic patient with a Chiari I malformation and cervicothoracic syrinx. T2-weighted sagittal magnetic resonance images show (A) tonsillar herniation extending to the posterior arch of $\mathrm{C} 1$ and (B) a large syrinx extending from C2 (A) to T9. (C) After surgery the size of the syrinx had decreased markedly. 
atively brief. In patients followed for several years, however, their postoperative neurologic improvement has been maintained and the size of their syrinx has remained diminished.

The increased incision length needed to enable adequate exposure of the pericranial graft is a disadvantage of this technique. T he procedure, however, has several advantages. First, the operation is simple. Second, it requires only a single incision. Third, it uses autologous tissue. Fourth, it avoids the occipital sinus. $F$ ifth, if repeat surgery requiring further intradural expansion or exploration is needed, the contralateral side is intact, minimizing difficulties related to a prior operation. In our experience, this technique has been associated with satisfactory clinical and radiologic outcomes and complications have been minimal.

\section{ACKNOWLEDGMENTS}

I am grateful to J. C orbitt for manuscript preparation, S. Teal for the illustration shown in Figure 1, and $\mathrm{J}$. M urphy for help in preparation of F igure 2. I thank the following physicians for patient referral: H. D eL eeuw, M. Farlow, J. H elfrich, F. K hairy, G.J. L oomis, B.G . M aybury, J. M unshower, T. Poe, E. Pretila, J. Vivio, J. W ojcieszek, and R. Yee.

\section{REFERENCES}

1. Batzdorf U. Syringomyelia, Chiari malformation, and hydromyelia. In: Youmans JR, ed. N eurological Surgery: A $C$ omprehensive R eference $G$ uide to the $D$ iagnosis and $M$ anagement of Neurosurgical Problems. 4th ed. Philadelphia, PA: W B Saunders; 1996:1090-1109

2. Ellenbogen RG , Z eidman SM . C raniovertebral decompression for Chiari malformation. In: Kaye AH, Black PM CL, eds. O perative $\mathrm{N}$ eurosurgery. N ew York, NY: C hurchill L ivingstone; 2000:1725-1741

3. Batzdorf U. M icrosurgery of syringomyelia and syringomyelia cord syndrome. In: Schmidek H H, ed. Schmidek \& Sweet $O$ perative N eurosurgical Techniques: Indications, M ethods, and Results. 4th ed. Philadelphia, PA: W B Saunders; 2000:1946-1954

4. Rhoton AL Jr. M icrosurgery of syringomyelia and the syringomyelia - Chiari complex. In: Schmidek $\mathrm{HH}$, ed. Schmidek \& Sweet O perative N eurosurgical Techniques: Indications, $M$ ethods, and Results. 4th ed. Philadelphia, PA: W B Saunders; 2000:1955-1969

5. M ilhorat TH, Chou, M W, Trinidad EM, et al. Chiari I malformation redefined: clinical and radiographic findings for 364 symptomatic patients. N eurosurgery 1999;44: 1005-1017

6. Kempe L G . O perative N eurosurgery. Vol 2: Posterior Fossa, Spinal C ord, and Peripheral N erve D isease. N ew York, NY: Springer-Verlag; 1970:14-23

7. $\mathrm{H}$ eiss, JD, Patronas $\mathrm{N}, \mathrm{D}$ eVroom H L, et al. E lucidating the pathophysiology of syringomyelia. J N eurosurg 1999;91: 553-562

\section{Commentary}

This is another variation on procedures for decompression of the posterior fossa for the treatment of C hiari I malformations. The bony decompression is the same as in other procedures. The authors, however, limit the dural opening and arachnoidal dissection and then make a dural graft from autologous pericranium. After treatment most of their patients improved, and all syringes resolved. The procedure requires a larger incision than usual but avoids using foreign materials for dural grafts and limits subarachnoid scarring. It is important to remember that the decompression must include the entire region that appears to be restricted on preoperative magnetic resonance imaging.

Chandranath Sen, M .D.1

Skull Base, volume 13, number 3, 2003. 1D epartment of N eurosurgery, St. L uke's R oosevelt H ospital, N ew York, N ew York. C opyright ( 2003 by Thieme M edical Publishers, Inc., 333 Seventh Avenue, New York, NY 10001, USA. Tel: +1(212) 584-4662. 1531-5010, p;2003,13,03,177,177,ftx,en;sbs00349x. 